\title{
The subjective time in a sentence
}

\section{[Субъективное время в предложении]}

\author{
Natalia V. Semenova — Nadezhda O. Grigoryeva
}

\section{DOI: 10.18355/XL.2017.10.02.09}

\begin{abstract}
Аннотация
Статья посвящена анализу скрытых различий синтаксических явлений, которые способствуют возникновению особого семантического и коммуникативного эффекта - субъективного времени, передаваемого ограниченной группой полипропозитивных предложений русского языка. К этой группе, по мнению авторов, относятся только те предложения, в которых актуализируется аспектуально-таксисная ситуация «одновременность целостных фактов» и используются уникальные темпоральные детерминанты типа в один миг, в одно мгновение, в одну секунду и под. Такие предложения представляют особый интерес для иноязычной аудитории.
\end{abstract}

Ключевые слова: субъективное время, таксис, скрытые различия синтаксических явлений

\section{1. Введение}

В русской грамматической теории давно была высказана идея о существовании имплицитных различий в сфере синтаксических явлений, которые в значительной степени предопределяют конструктивный, семантический и коммуникативный аспекты сложного предложения. Эта идея получила научное описание в синтаксической концепции В.А. Белошапковой, которая отметила, что для адекватного описания структуры сложного предложения и той стороны его семантики, которая создается этой структурой, необходимо уметь видеть скрытые различия синтаксических явлений (Beloshapkova, 1977: 235-236; Semenova, 2010).

Предмет нашего рассуждения- «субъективное время»- обязан своим существованием как раз таким скрытым (или имплицитным) различиям, которые обнаруживаются в полипропозитивных предложениях русского языка и оказывают значительное влияние на выражение таксисных значений. Говоря о таксисе, мы имеем в виду ту функционально-семантическую категорию, которая отражает одну из сторон общей идеи времени, а именно: временную сопряженность действий, выражаемую через отношения разновременности/одновременности.

В любом предложении, где идет речь о нескольких действиях, как правило, устанавливается порядок их наступления: они квалифицируются как предшествующие, следующие или одновременные по отношению друг к другу. Но иногда этот порядок оказывается несущественным для говорящего, и тогда он передает их комплексно, как в примере типа Он кривился, бледнел, пенился; он грозил кулаком. Так шли они несколько шагов. Князя он не иеремонился нимало, точно был один в своей комнате, потому что в высшей степени 
считал его за ничто (Ф.М. Достоевский. Идиот (1869)) $)^{14}$. В этом случае говорят о недифференцированном таксисе. Действительно, без дополнительного объяснения, мы не можем однозначно интерпретировать действия кривился, бледнел, пенился, грозил кулаком как разновременные или одновременные: возможно, часть их была последовательна, а часть одновременна - контекст не дает нам никаких оснований для той или иной интерпретации.

Для того чтобы избежать подобной двусмысленности, говорящий обычно использует различные темпоральные средства, уточняющие порядок следования действий, такие, как сначала, потом, прежде, раньше, одновременно и под. Используя традиционный репертуар лексикограмматических средств родного языка, говорящий часто даже не подозревает, что во многих случаях их адекватное понимание может составить определенную трудность для иноязычной аудитории. К таковым, на наш взгляд, относится ограниченная группа специальных темпоральных показателей одновременности типа в ту же (самую) секунду, в тот же (самый) момент, в тот же (самый) миг, в то же (самое) мгновение/в одно мгновение, обозначающих минимальный, или «очень короткий», период времени (Slovar' russkogo jazyka, 1999). Мы полагаем, что использование данных языковых средств в определенных аспектуально-таксисных условиях создает особый семантический и коммуникативный эффект, который заключается в дополнительных смысловых оттенках временного соотношения действий. Этот эффект мы и называем «субъективным временем». Предложения, в которых он проявляется, неоднозначно понимаются в разной языковой аудитории, чем и представляют немалый лингвокультурный интерес. Так, иностранец, услышав или прочитав предложение Пеночка всхлипнула и в тот же миг увидела своего единственного друга (Марина Вишневецкая. Слон и пеночка // «Трамвай», (1990)), скорее всего, без колебаний скажет, что в нем описываются действия одновременные, потому что здесь есть прямое лексическое указание $b$ тот же миг. Русский же человек, с высокой степенью вероятности, проигнорирует это лексическое указание и интерпретирует действия всхлипнула и увидела как последовательные, отметив, что осуществить их в один миг невозможно, поскольку он слишком краток и в русском языковом сознании не ассоциируется с несколькими операциями. Еще более категоричен будет русскоязычный слушатель/читатель в определении разновременного, а не одновременного характера действий в следующем предложении $\boldsymbol{B}$ одно мгновение люди исчезлииз глаз - один за другим (А. А. Фадеев. Молодая гвардия (1943-1951)), где имплицитно указывается на несколько действий, производимых разными субъектами. Основным аргументом будет утверждение, что в предложении есть лексическое указание на последовательный дистрибутивный характер совокупного действия «исчезли»- один за другим, которое прямо противоречит указанию на то, что исчезновение нескольких субъектов произошло в одно мгновение.

Цель данной статьи - продемонстрировать коммуникативную специфику русских предложений, в которых актуализируется субъективное время, и

\footnotetext{
${ }^{14} \mathrm{~B}$ статье используются в качестве иллюстративного материала примеры только из Национального корпуса русского языка и параллельного англо-русского корпуса. При этом сохраняется орфография и пунктуация источника.
} 
описать грамматические механизмы, способствующие такой актуализации. Анализ ограничен рамками только одной аспектуально-таксисной ситуации «одновременность целостных фактов», поскольку именно эти грамматические условия оказываются наиболее показательными для демонстрации интересующего нас семантического эффекта. Признавая фундаментальность синтаксической связи как организующего «начала» синтаксической системы языка, мы избираем дифференцированный подход к разным типам предложений, учитывая особенности техники связи компонентов в подчинительных и сочинительных конструкциях.

\section{2. Методология}

Основным методом настоящего исследования является функциональносемантический в том его варианте, который был заявлен Санкт-Петербургской школой функциональной грамматики под руководством А.В. Бондарко. В рамках этого направления было предложено понятие «аспектуально-таксисная ситуация» (АТС), которая рассматривается как «типовая содержательная структура», связанная «с функцией выражения сопряженности действий в составе предикативного комплекса, элементы которого относятся к одному и тому же временному плану (прошлого, настоящего или будущего)» (Bondarko, 2002: 516). Типология АТС - это, по сути, типология категориальных значений таксиса.

Термин действие понимается далее в широком смысле, как родовое понятие, т.е. в отвлечении от того конкретного содержания понятия «действие», которое предполагает различие между активным действием и пассивным состоянием, наличием, проявлением каких-либо свойств или отношений и является объектом семантических классификаций предикатов. Когда мы говорим действие, мы, естественно, подразумеваем ситуаиию, на которую оно указывает, и в этом смысле термин «действие» является синонимом термину «ситуация».

Основными параметрами при характеристике АТC считаются те, которые позволяют представить действия и обозначаемые ими ситуации с точки зрения их распределения и протекания во времени. Они отражают аспектуальную категоризацию русского глагола и представлены в языковом сознании в виде соответствующих концептов, которые традиционно именуются «признаками». Это: «ограниченность/неограниченность пределом, наличие/отсутствие внутреннего предела, представление действия как протекающего процесса или как ограниченного пределом целостного факта, кратность, длительность, выделение той или иной фазы действия (фазовость), актуальность последствий действия для более позднего временного плана (перфектность), различие между собственно действием, состоянием и отношением» (Bondarko, 1987: 41).

В статье подробно рассматривается только одна АТС «одновременность целостных фактов». «Целостный факт» в работе понимается как аспектуальная модель завершившегося, предельного, непроцессного и не делимого на какие-либо фазы, действия, которое в русском языке может передаваться обеими видовыми формами (Semenova, 2004). При этом формы совершенного вида (СВ) трактуются как специализированные средства выражения такого действия, а формы несовершенного вида (НСB) - как маргинальные, поскольку они способны указывать на целостность только в общефактическом значении, которое допускает нейтрализацию процессных 
характеристик действия в сочетании с признаком «нехарактеризованности»его протекания во времени. Срав.: Bы зашли (CB)/заходили (HCB) к врачу? Bы позвонили (СВ)/звонили (НСВ) врачу?; Вы поспали (CB)/спали (НСВ)?

Материалом для исследования послужили примеры, отобранные методом сплошной выборки из текстов художественной и публицистической литературы, представленной в Национальном корпусе русского языка. Для сравнения, там, где это необходимо, привлекались и примеры из параллельного англо-русского корпуса. Всего проанализировано около 10000 предложений.

\section{3. Два замечания об общих грамматических условиях актуализации АТС «одновременности целостных фактов»}

Первое замечание относится к области грамматической семантики интересующих нас предложений. По мнению аспектологов, в любом естественном языке «одновременность» может быть представлена тремя субзначениями, которые «характеризуют все теоретические возможности заполнения двумя ситуациями одного периода времени» (Hrakovskij, 2009: 31). Эти значения таковы: 1) первая ситуация занимает тот же временной период, что и вторая ситуация, например: Пока Петя делал уроки, Маша читала; 2) вторая ситуация локализуется в рамках временного периода, занимаемого первой ситуаций, например: Когда Петя делал уроки, в комнату вошла Маша; 3) первая ситуация локализуется в рамках временного периода, занимаемого второй ситуацией, например: Когда в комнату вошла Маша, Петя делал уроки (Hrakovskij, 2009: 30). Значение (1) - это полная одновременность, а (2) и (3) частичная. В АТС «одновременность целостных фактов» актуализируется значение только полной одновременности.

Следующее замечание имеет отношение к способам «формальной упаковки», или синтаксического оформления, рассматриваемой АТС. И в этой связи мы отмечаем, что «одновременность целостных фактов» может выражаться исключительно в рамках гипотаксиса, причем в ограниченной группе синтаксических конструкций - сложноподчиненных предложениях с придаточными времени или соотносимых с ними сложноподчиненных предложениях с придаточными условия. Происходит это только при участии глаголов СВ и глаголов НСВ в общефактической функции. А в паратаксисе, то есть в различных видах сложносочиненных и бессоюзных предложений, основанных на сочинительной синтаксической связи, а также в простых предложениях с однородными сказуемыми, этот тип таксисного соотношения «в чистом виде» не актуализируется: если соблюдаются аналогичные условия, то есть используются соответствующие аспектуальные формы для указания ряда целостных фактов без какого-либо уточнения, что они могли быть одновременными или последовательными, то передается значение временной недифференцированности, а не одновременность, как, например, в следующих примерах: Развернулось новое строительство. Застучали топоры, завизжсали пильь (Виктор Безотосный. "Пожар способствовал ей много к украшенью» // «Знание-сила», (2012)); «Неужели перо?» Вгляделся - действительно, перо. Барнабели, - произнесла в этот момент женщина у него за спиной. Кузьменко побледнел и вздрогнул (Сергей Довлатов. Дорога в новую квартиру (1987)); Tут он только опомнился. Отшитнулся, встряхнул руку, как будто отбрасывая что-то липкое, и отошёл в сторону (Ю. О. Домбровский. Обезьяна приходит за своим черепом, часть 2 (1943-1958)). Аспектуально маркированные паратаксисные конструкции вообще предрасположены более к 
недифференцированному выражению таксисных значений (Semenova, 2002). Данное обстоятельство наводит на мысль о том, что обозначение одновременности действий в их событийном аспекте по преимуществу имеет метаязыковую природу: подчинительная связь, базирующаяся на логических основаниях, по-видимому, более адекватна для передачи языковой (семантической) субкатегории одновременности.

\section{4. Выражение одновременности целостных фактов в сложноподчиненных предложениях с придаточными времени и условия}

Одновременность целостных фактов в сложноподчиненных предложениях с придаточными времени и условия выражается довольно отчетливо, и во многом этому способствует сама грамматическая природа этих синтаксических конструкций, в частности - наличие специализированных союзных средств. Однако нужно помнить о том, что сами по себе союзные средства «гарантировать» выражение таксисного значения полной одновременности, как и вообще какого-либо другого значения, не могут (Grigor'eva, 2013). В этой связи вспомним удивительно тонкое замечание Л.П. Размусена, которое он сделал еще в конце XIX века. «В обыденной жизни редки бывают случаи полного совпадения действий с их началом, продолжением и концом ..., - писал ученый. - Временные союзы столь же редко означают строгую одновременность в смысле точного совпадения времени одного действия со временем другого, как определение мест, вроде «там ... где» означает строгое совпадение пространства, занимаемого другими» (Razmusen, 1891: 414).

Уместно предположить, что актуализация одновременности в рассматриваемых синтаксических конструкциях во многом определяется особенными свойствами их глагольно-предикативных компонентов во всей совокупности актантных распространителей. И это действительно так. В таких предложениях используется ограниченный круг глагольной лексики - только предикаты достижения, происшествия. Представляемое ими действие совершается целостно «по природе», сразу от начала до конца, «само возникновение действия знаменует собой достижение предела» (Maslov, 2004: 28). Поэтому признак достижения предела является одновременно условием и единственными способом проявления обозначаемого глагольного действия. Видовые формы в сложноподчиненных предложениях с придаточными времени стандартно актуализируют конкретно-фактическое значение СВ (гораздо реже некоторые из соотносимых форм могут иметь перфектно-результативное значение). При этом одновременность действий обязательно подчеркивается лексическими средствами: соответствующими временными обстоятельствами или частицами типа как раз, в ту (же самую) секунду, в тот (же самый) момент, в то (же самое) мгновение, в то (же самое) время, в тот (же самый) миг и под. Например: Катя вышла из столовой, как раз когда мы шагнули друг $\kappa$ другу через какие-то чемодань (Вениамин Каверин. Два капитана (19381944)); В ту самую секунду, как Пьер сделал это и произнес эти слова, он почувствовал, что вопрос о виновности его жены <... был окончательно и несомненно решен утвердительно (Л. Н. Толстой. Война и мир. Том второй (1867-1869)); Окончательно пес очнулся глубоким вечером, когда звоночки прекратились и как раз в то мгновение, когда дверь впустила особенных посетителей (М. А. Булгаков. Собачье сердие (1925)); В то самое время как императоры вошли в павильон, он посмотрел на часы и не забыл посмотреть 
опять в то время, когда Александр вышел из павильона (Л. Н. Толстой. Война и мир. Том второй (1867-1869)); В тот миг, когда опрокинулся мой плот, в тот именно миг, там, в глубине вод, я увидел такую же сеть из паутины (Владимир Брагин. В стране дремучих трав (1962)).

В условных предложениях аналогичное значение всегда осложняется дополнительным семантическим признаком узуальности, «обычности» и/или «типичности», поскольку по структуре такие предложения являются кратнопарными конструкциями: Если вы приедете в обычный день и начнете петь акафист, в тот же момент к вам подойдут туреикие смотрители, $и$ сделают замечание (Александр Бугаевский. О происхождении Санта-Клауса // «Русский репортер», № 48 (78), 18-25 декабря 2008, 2008). Узуальный характер действий может «поддерживаться» особым аспектуальным значением глагольных форм - общефактической функцией $\mathrm{HCB}$, срав..: И если кто-то умирал - то в ту же секунду рождался другой (Михаил Гиголашвили. Экобаба и дикарь (1998-2007) // «Зарубежные записки», (2009)).

Как видим, во многих случаях для подчеркивания одновременности осуществляемых действий автор выбирает экспрессивные временные детерминанты, указывающие на очень короткий, или, точнее, сверхкраткий период. Но обладают ли моменты, миги, мгновения, секунды объективной мерой длительности? Если в отношении секунды и момента следует ответить положительно, то в отношении мигов и мгновений мы этого констатировать не можем. Строго говоря, и секунды с моментами в русском языковом сознании «вещь» довольно растяжимая: если в телефонном разговоре вас попросят подождать секунду или секундочку (равно как и момент), будьте уверены, что ваше ожидание продлится гораздо дольше, срав.: - A кто его спрашивает? осведомилась вышколенная секретарша. - Скажите Сорин, просто Сорин. Секундочку. В трубке заиграла нехитрая электронная мелодия. Секунд через двадцать раздался щелчок, и уже знакомый голос произнес: - Сорин? (Петр Галиикий. Опасная коллекиия (2000)). Собственно говоря, секунда вообще может потерять свои астрономические временные границы, о чем нам недвусмысленно свидетельствует следующий пример: - Нет, мне некогда, $\boldsymbol{я}$ только на одну секундочку, - отвечал Степан Аркадьич. Он распахнул пальто, но потом снял его и просидел целый час, разговаривая с Левиным об охоте и о самых задушевных предметах. - Ну, скажи же, пожалуйста, что ты делал за границей? где был? (Л. Н. Толстой. Анна Каренина (1878)). Подобные лексические средства используются русским человеком для описания не объективного, а субъективного, «переживаемого» и эмоционально насыщенного времени. Их основной дейктической функцией является указание не на период времени, а на точку на временной оси, в которую, по воле говорящего, способен вместиться целый фрагмент жизни. Срав. описание мига и мгновения у А. Кабакова: $B$ тот миг, когда я запнулся, подбирая слова, произошло одновременно столько, что когда я пытался потом это вспомнить, мне казалось и до сих пор кажется, что мгновение это длилось по крайней мере полчаса (Александр Кабаков. Последний герой (1994-1995)).

\section{5. Способы представления одновременности целостных фактов в паратаксисных конструкциях}

Если в различных видах сложносочиненных и бессоюзных предложений, основанных на сочинительной синтаксической связи, а также в простых предложениях с однородными сказуемыми, мы обнаруживаем несколько 
глаголов СВ, то мы должны интерпретировать передаваемое ими таксисное соотношение прежде всего как неопределенное по временному параметру. Это означает, что само по себе такое предложение не дает нам абсолютно никаких указаний на разновременность или одновременность. Причем, если обозначаемых действий больше, чем два, то, возможно, часть их могла происходить одновременно, а часть - последовательно, как, например, в таких предложениях: В сенях он натолкнулся на Гайнана, не заметил его, испугался, вздрогнул и воскликнул сердито: - Что за черт! Это ты, Гайнан? Кто тут? (А. И. Куприн. Поединок (1905)); С галёрки плеснуло смешком, а Бенгальский вздрогнул и выпучил глаза (М. А. Булгаков. Мастер и Маргарита, часть 1 (1929-1940)).

Разрешению временной неопределенности в рассматриваемых сложных синтаксических конструкциях, естественно, способствуют различные лексические темпоральные указатели, вводимые в высказывание говорящим с целью уточнения последовательности передаваемых действий. Но если в качестве таковых используются момент, миг, мгновение или секунда, то их темпорально-дейктическая функция практически полностью нейтрализуется. Они становятся своеобразными стилистическими маркерами и сигнализируют об эмоциональном, а не объективном восприятии времени действий. Мы полагаем, что коннотативный компонент в структуре лексического значения таких лексических единиц гораздо более значим, чем концептуальный. Иначе говоря, референциальный момент подобных показателей времени составляет часть отрезка времени, занимаемого описываемой ситуацией, то есть задает включенное время, но это время всегда интуитивное: оно по воле мыслящего субъекта может растягиваться, сжиматься, теряя всякие границы. Поэтому, на наш взгляд, такие временные показатели одновременности в рассматриваемых синтаксических условиях никогда не употребляются в своем первичном темпоральном значении, а используются, скорее, как актуализаторы «раритетности» для говорящего передаваемых событий. Именно поэтому секунды, моменты, мгновения, миги растягиваются и включают в себя несколько действий, что в принципе невозможно в реальном мире, особенно если речь идет о действиях одного субъекта, срав.: [Лавреикий не сразу понял, что такое он прочел; прочел во второй раз - и голова у него закружилась, пол заходил под ногами, как палуба корабля во время качки]. Он и закричал, и задохнулся, и заплакал в одно мгновение (И. С. Тургенев. Дворянское гнездо (1859)). Совершенно точно, что чисто физиологически одновременно осуществить подобные действия нельзя, но для субъекта, переживающего высокий накал страстей, все кажется именно таким, и потому именно так описывает их автор. Применительно к таким случаям мы предлагаем говорить о «квазиодновременности» выражаемых действий. В аналогичных примерах с совокупным субъектом или разными субъектами это значение проявляется еще отчетливее. Срав.: И после этого прямо на Петьку, как с неба, посыпались моряки. Настоящие моряки в настоящих бескозырках, в тельняшках, в черных бушлатах, с огромными усатыли лицами и иирокими, как двери в избу, плечами. В одно мгновение все вокруг захохотало, закричало, засвистело, задвигалось и заходило ходуном (Андрей Геласимов. Степные боги (2008)); Я остановился, и отряд в тот же миг застыл на месте (Карен Шахназаров. Курьер (1986)). Сама категория времени здесь кардинально меняет свою природу: она перестает быть «количественной» и становится «качественной». «“Качественность” времени задается событиями, его заполняющими, - считает 
Е.С. Яковлева. - Именно такое время относится к сфере самосознания человека» (Jakovleva, 1994: 138).

«Квазиодновременость» относится к сфере проявления субъективного времени, которое, на наш взгляд, обладает ярким культуроспецифичным компонентом. Так, английский язык практически всегда дает нам нейтральный в стилистическом отношении вариант in one moment там, где русский человек предпочтет употребить экспрессивное русское выражение в одно мгновение для контекстов с «квазиодновременными» несколькими целостными фактами. Это довольно недвусмысленно демонстрирует параллельный англо-русский корпус. Например, в следующих случаях английский темпоральный указатель in one moment двумя разными русскими переводчиками был переведен именно как 8 одно мгновение:

1) Then all in one moment there was arending of the blue wall (like a curtain being torn) and a terrible white light from beyond the sky, and the feel of Aslan's mane and a Lion's kiss on their foreheads and then - the bark bedroom in Aunt Alberta's home in Cambridge (Clive Staples Lewis. The Chronicles of Narnia. The Voyage of the 'Dawn Treader' (1952) - Все произошло в одно мгновение: синяя стена разошлась, как рвущаяся занавеска, откуда-то с неба полился ужасающий бельй свет, дети почувствовали прикосновение гривы Аслана и поцелуй Льва на своем лбу, а затем они вдруг очутились в задней спальне в доме тети Альберты в Кембридже (Клайв Стейплз Льюис. Хроники Нарнии. Плавание «УтреннегоПутника» (Г. А. Островская, 1991);

2) I heard the machine-guns and rifles firing across the river and all along the river. There was a great splashing and I saw the star-shells go up and burst and float whitely and rockets going up and heard the bombs, all this in a moment, and then I heard close to me some one saying "Mama Mia! Oh, mama Mia!" (Ernest Hemingway. Farewell to Arms (1929)) - Я сльишал пулеметную и ружейную стрельбу за рекой и по всей реке. Раздался громкий всплеск, и я увидел, как взвились осветительные снаряды, и разорвались, и залили все бельм светом, и как взлетели ракеты, и усльшиал взрывы мин, и все это в одно мгновение, и потом я усльшал, как совсем рядом кто-то сказал: «Матта тіа! O, татта тіа!» (Эрнест Хемингуэй. Прощай, оружие! (Е. Калашникова, 1936)).

И даже совершенно нейтральное английское выражение in a minute русские переводчики в эмоционально отмеченных контекстах предпочитают заменять привычным русским показателем «раритетности событий» в одно мгновение. Например, следующее предложение, как свидетельствует параллельный англо-русский корпус, также было переведено с его помощью: Still Dori did not let Bilbo down. He waited till he had clambered off his shoulders into the branches, and then he jumped for the branches himself. Only just in time! A wolf snapped at his cloak as he swung up, and nearly got him. In a minute there was a whole pack of them yelping all round the tree and leaping up at the trunk, with eyes blazing and tongues hanging out. (J. R. R. Tolkien. The Hobbit (1937)) - И всё-таки Дори не бросил хоббита в беде: он дождался, пока тот перелез с его плеч на дерево, и только тогда подпрыгнул и ухватился за нижнюю ветку. Как раз вовремя! Волк щелкнул зубами и чуть не сдёрнул Дори за плащ.. В одно мгновение вся стая сгрудилась вокруг дерева, волки с воем запрыгали у ствола, глаза их горели, языки свисали наружу (Дж. Р. Р. Толкин. Хоббит (Н. Рахманова, 1976)).

Справедливости ради следует сказать, что иногда лексическое средство 8 одно мгновение может функционировать в русском языке и в 108 
обстоятельственно-временной функции, но и в этом случае оно стилистически не нейтрально, так как всегда указывает на «смещение по ряду интенсивности» в сторону преуменьшения и участвует в такой языкотворческой операции, как литота, срав.: Все та же непонятная тоска, что уже приходила на балконе, пронизала все его существо. Он тотчас постарался ее объяснить, и объяснение было странное: показалось смутно прокуратору, что он чего-то не договорил с осужденным, а может быть, чего-то не дослушал. Пилат прогнал эту мысль, и она улетела в одно мгновение, как и прилетела (М. А. Булгаков. Мастер и Маргарита (1929-1940)). Здесь в одно мгновение указывает на то, что мысль улетела мгновенно, то есть очень быстро, за короткий период времени. Показательно, что в своем совместном переводе и русский, и английский переводчики, тонко ощущая этот семантический нюанс, использовали соответствующее английский эквивалент instantly: The same incomprehensible anguish that had already visited him on the balcony pierced his whole being. He tried at once to explain it, and the explanation was a strange one: it seemed vaguely to the procurator that there was something he had not finished saying to the condemned man, and perhaps something he had not finished hearing. Pilate drove this thought away, and it flew off as instantly as it had come flying (Mikhail Bulgakov. Master and Margarita (Richard Pevear, Larissa Volokhonsky (1979)).

Но самое интересное, что русские переводчики предпочитают использовать эмоционально-экспрессивные слова типа миг и мгновение даже тогда, когда в оригинале вообще нет никакого лексического указания на временные обстоятельства осуществления нескольких действий. Именно так поступил Г. Косов при переводе следующего текстового отрезка «Ангелов и демонов» Д. Брауна: Robert Langdon had no idea where he was or how long he had been unconscious when he opened his eyes and found himself staring up at the underside of a baroque, frescoed cupola. Smoke drifted overhead. Something was covering his mouth. An oxygen mask. He pulled it off. There was a terrible smell in the roomlike burning flesh. Langdon winced at the pounding in his head. He tried to sit up. A man in white was kneeling beside him. "RIPOSATI!" the man said, easing Langdon onto his back again. "SONO IL PARAMÉDICO." Langdon succumbed, his head spiraling like the smoke overhead. WHAT THE HELL HAPPENED? Wispy feelings of panic sifted through his mind. "SÓRCIOSALVATORE," theparamedicsaid. "Mouse ... savior" (DanBrown. AngelsandDemons (2000)) - Когда Роберт Лэнгдон открыл глаза и обнаружил, что видит над собой расписанный фресками купол в стиле барокко, он не мог понять, где находится и сколько времени провалялся без сознания. Высоко над головой плавал дымок. Какой-то предмет закрывал его рот и нос. Кислородная маска. Ученый содрал с лица прибор, и в тот ж⿻е миг ему в ноздри ударил ужасный запах. Запах сгоревщей плоти. Стучащая в висках боль заставила его скривиться. Когда он предпринял попытку сесть, рядом с ним присел человек в белом халате. - Riposati! - сказал человек в белом. - Sono il paramedico. «Лежите! - машинально перевел Лэнгдон. - Я фельдшер». Затем он снова едва не потерял сознание. Голова кружилась, как дымок под куполом. Что, черт побери, произошло? Им снова стала овладевать паника. - Sorcio salvatore, - сказал человек, представившийся фельдшером. Мышионок ... спаситель (Дэн Браун. Ангель и демоны (Г. Косов, 2004)).

\section{6. Заключение}

Итак, последовательный анализ конструктивного, семантического и коммуникативного аспектов русского сложного предложения приводит нас к 
выявлению новых эффектов, которые подчас оказываются культуроспецифичными и, несомненно, могут вызвать неподдельный интерес у иноязычной аудитории. К таковым, в частности, мы относим особенности проявления субъективного времени в полипропозитивных предложениях, специализирующихся на выражении «одновременности целостных фактов». Очень часто, как показывает наш материал, эксплицитное языковое указание на полную одновременность обозначаемых действий противоречит однозначному смысловому прочтению их как одновременных, и этот семантический эффект является результатом взаимодействия особых глагольно-предикативных форм, техники их связи в полипропозитивной конструкции (подчинение или сочинение) и использования уникальных темпоральных лексических средств типа в ту же (самую) секунду, в тот же (самый) момент, в тот (же самый) миг, в то же мгновение/в одно мгновение. Главный же коммуникативный эффект таких предложений состоит в том, что говорящему в данном случае, по-видимому, абсолютно безразлично, как и в какой последовательности происходили или могли бы произойти описываемые им действия в реальности. Для него почему-то оказывается гораздо важнее выразить собственную, субъективную, интерпретацию описываемого как «раритетного», сверхзначимого комплексного события. Именно потому он особым образом строит синтаксическую конструкцию, отбирает особые лексические и грамматические средства, как будто интуитивно ощущая те скрытые различия синтаксических явлений, о которых писала В.А. Белошапкова и которые по сути своей выходят за рамки синтаксиса в традиционном его понимании.

\section{Bibliographic references}

BELOSHAPKOVA, V.A. 1977. Sovremennyj russkij jazyk. Sintaksis: Ucheb. posobie dlja filol. special'nostej un-tov. Moskva: Vysshaja shkola.

BONDARKO, A.V. 1987. Aspektual'nost'. In: Teorija funkcional'noj grammatiki: Vvedenie. Aspektual'nost'. Vremennaja lokalizovannost'. Taksis. Leningrad: Nauka, pp. 40-62.

BONDARKO, A.V. 2002. Taksisnye (aspektual'no-taksisnye) situacii. In: Teorija znachenija $\mathrm{v}$ sisteme funkcional'noj grammatiki: Na material russkogo jazyka. Moskva: Jazyki slavjanskoj kul'tury. (Studia philologica), pp. 516-517. ISBN 5-94457021-0.

GRIGOR'EVA, N.O. 2013a. Konstrukcii s polifunkcional'nymi sluzhebnymi slovami: tekstovyj potencial. In: Medialingvistika, vol. 2, pp. 134-137. ISSN 2312-0274.

HRAKOVSKIJ, V. S. 2009. Taksis: semantika, sintaksis, tipologija. In: Tipologija taksisnyh konstrukcij. Moskva: Znak. pp. 11-113. ISBN 978-5-9551-0330-3

JAKOVLEVA, E.S. 1994. Fragmenty russkoj jazykovoj kartiny mira (momenty prostranstva, vremeni i vosprijatija). Moskva: Izdatel'stvo «Gnozis». ISBN 5-73330424-8.

MASLOV, JU.S. 2004. Izbrannye trudy: Aspektologija. Obshhee jazykoznanie. Moskva: Jazyki slavjanskoj kul'tury. ISBN 5-94457-187-X.

NACIONAL'NYJ KORPUS RUSSKOGO JAZYKA. [online]. [cit. 2016-16-01]. URL: <http://www.ruscorpora.ru>.

RAZMUSEN, L.P. 1891. O glagol'nyh vremenah i ob otnoshenii ih $\mathrm{k}$ vidam v russkom, nemeckom i francuzskom jazykah. In: Zhurnal ministerstva narodnogo prosveshhenija, n. 6 (Ijun'). S.-Peterburg, pp. 376-417. 
SEMENOVA N.V. 2002. Aktualizacija nedifferencirovannogo taksisa v aspektual'no markirovannyh kontekstah. In: Osnovnye problem russkoj aspektologii. S.-Peterburg: Nauka, pp. 185-189. ISBN 5-02-028527-7.

SEMENOVA N.V. 2010. Nedifferencirovannaja sintaksicheskaja svjaz' v koncepcii V.A. Beloshapkovoj. In: Lingvisticheskie idei V.A. Beloshapkovoj i ihvoploshhenie v sovremennoj rusistike: kollektivnaja monografija. Tjumen': MandriKa, pp. 109-116. ISBN 5-93020-450-0.

SEMENOVA, N.V. 2004. Kategorija taksisa v sovremennom russkom jazyke: Avtoref. dissertacii doktora filol. nauk. Moskva.

SLOVAR' RUSSKOGO JAZYKA. 1999. V. 2. K - O. / RAN, In-t lingvisticheskih issledovanij; Pod red. A.P. Evgen'evoj. 4-e izd., ster. Moskva: Rus. jaz., Poligrafresursy. ISBN 5-200-02674-1 («Russkij jazyk»), ISBN 5-87548-045-9 (Poligrafresursy).

Words: 4287

Characters: 32954 (18,3 standard pages)

Prof. Natalia V. Semenova, Doctor of Philology,

Department of Russian as a Second Language

National Research Nuclear University MEPhI (Moscow Engineering Physics Institute)

Kashirskoye shosse, 31

115409, Moscow

Russia

nvsemenova@mail.ru

Assoc. prof. Nadezhda O. Grigoryeva, $\mathrm{PhD}$,

Department of Russian Language and Theoretical Linguistics

Southern Federal University

Bolshaya Sadovaya street, 105/42

344006, Rostov-on-Don

Russia

ngreg25@yandex.ru 